\title{
CONFISCATION OF CHURCH PROPERTY IN THE YENISEI PROVINCE (PERIODIZATION AND OUTCOME)
}

(C) 2017

Vdovin Alexander Sergeevich, candidate of historical sciences, professor of Museology and Cultural Heritage Department

Bobrik Iliya Eugenievich, student of History Faculty

Krasnoyarsk State Pedagogical University named after V.P. Astafiev (Krasnoyarsk, Russian Federation)

Abstract. The following paper focuses on the confiscation of church property in the Yenisei province, which was held from March 1922 to March 1923. Hunger in Volga Region was the reason for the campaign. The authors on the basis of central and regional archives review the results of the campaign, which was described earlier in the regional historiography. They also give periodization of the process in the province. The authors believe that the confiscation of church property in the Yenisei province took place in three uneven stages. The last phase was delayed for more than six months. The periodization is based on Krasnoyarsk and Moscow correspondence about the campaign. Yenisei province as most lagging in the campaign finished confiscation by the end of 1922 . The authors have traced the path of church property of the local financial departments to the provincial finance department and then from Krasnoyarsk to Yekaterinburg and Moscow.

Keywords: church and Soviet State; church property; confiscation; Russian Orthodox Church; Yenisei province; Pomgol; Yenisei Siberia; religious organizations; hunger in Volga Region; Yenisei diocese; church silver; antireligious policy; economic policy.

УДК 94 (73)

\section{ЗАПАСНАЯ СТОЛИЦА СССР: ОЦЕНКИ АМЕРИКАНСКОЙ ПРЕССЫ И СПЕЦСЛУЖБ}

(C) 2017

Буранок Сергей Олегович, доктор исторических наук, доцент кафедры всеобщей истории, права и методики обучения Левин Ярослав Александрович, кандидат исторических наук, младший научный сотрудник кафедры всеобщей истории, права и методики обучения

Соколова Анна Вячеславовна, студент исторического факультета

Самарский государственный социально-педагогический университет (2. Самара, Российская Федераџия)

Аннотаиия. В данной статье впервые в самарском краеведении предпринято исследование того, какое место и значение г. Куйбышев занимал в общественном мнении союзников СССР. Став запасной столицей, Куйбышев перестал быть только одним из региональных центров Советского Союза, превратившись в город, известный и значимый во всем мире. В данной статье использованы многие уникальные документы США о Куйбышеве времен войны. Кроме того, на их основе проанализированы становление и восприятие образа запасной столицы в американском обществе. Изучение истории Куйбышева как второй столицы под таким углом является важным для имагологии, краеведения, компаративистики. Проведенное исследование показало, как конструировался образ города Куйбышева в условиях Второй мировой войны, как менялось его восприятие. Также важно отметить, что в статье используются и данные спецслужб США, что позволяет понять, какое место Куйбышеву на тот момент отводили представители разведывательного сообщества Америки. Изучение образа Куйбышева в оценках американских спецслужб открывает исследователям возможность познакомиться с их работой с нового ракурса. Помимо этого в статье проанализировано влияние тех или иных журналистов на формирование образа Куйбышева. Сделанные в данной статье выводы, а также введение в оборот новых документов позволит в будущем углубить и расширить данную тему.

Ключевые слова: Вторая мировая война; Великая Отечественная война; Куйбышев; Самара; Самарская область; имагология; запасная столица; Федеральное бюро расследований; Ассошиэйтед Пресс; Соединенные Штаты Америки; Генри Кэссиди; Эдди Гилмор; Генри Шапиро; Уолтер Керр; Арчибальд Стил; спецслужбы; Пёрл-Харбор; Тихоокеанская война.

«Куйбышев военных лет» - различным аспектам этой многогранной темы посвящено множество публикаций. В них досконально исследована экономика Куйбышевской области, деятельность партийных, государственных и общественных структур, культурная жизнь запасной столицы, вклад работников науки и образования в победу, демографическая ситуация и т.д. Но все еще остаются малоизученные проблемы истории Куйбышева военного периода, одной из которых является восприятие «военной столицы» общественностью союзников. Важность изучения подобной проблемы заключается не только в расширении научных знаний по истории Самары, но и в конкретизации образа «советского союзника», сформировавшегося у американцев и англичан в 1941-1945 гг. Первые сообщения о Куйбышеве в США появляются 18-20 октября 1941 г., а уже 2224 октября 1941 г. почти каждая газета США написала про Куйбышев.

Вынужденный переезд дипломатов и журналистов в Куйбышев сыграл большую роль в формировании общего позитивного настроя общественности США и Великобритании: 22 октября многие корреспонденты написали в свои редакции, что через Куй- 
бышев постоянно идут войска с востока $[1$, p. 2,$4 ; 2$, p. 5]. Некоторые остроумные американские журналисты называли их «сибирские дивизии», «монгольские дивизии». По словам известного военного обозревателя «Ассошиэйтед пресс» Дэвида Макензи, Куйбышев в глазах американцев превратился не просто в «столицу военного времени», а в место сосредоточения резервов, которые спасут Москву [3, p. 2 , 3]. День 22 октября 1941 г. сделал Куйбышев понастоящему известным городом по всей Англии и Америке: более 70 крупных центральных и небольших провинциальных газет содержали информацию о нем.

В таком информационном потоке были сведения, конкретизирующие образ Куйбышева: статьи в прессе США кратко пересказывали историю города, уровень развития его промышленности, месторасположение. Появляется 23 октября на страницах англоамериканских газет и другой насущный для союзников вопрос: когда дипломатический корпус вернется в Москву. В «Albuquerque Journal» приведены слова анонимного английского обозревателя, который утверждает, что «наступление Гитлера на Москву настолько замедлилось, что в Куйбышеве никто не будет удивлен, если в ближайшие дни поступит распоряжение возвращаться в Москву» $[4$, p. 1]. Но в последующие дни (24-28 октября) в развитии представлений о Куйбышеве в англо-американской прессе наступает вынужденный перерыв, связанный с тревожными сообщения о ходе боев под Москвой.

Сам город не исчезает со страниц газет - большинство военных сводок и коммюнике идут с пометкой «из Куйбышева». 25 октября появляется только одна новая, относительно большая статья, написанная Арчибальдом Стилом. Начинается статья не совсем обычно для хроники того времени: «Названный Самарой, Куйбышев был переименован после революции в честь отца пятилеток. Каждый дюйм Куйбышева доказывает, что это типичный русский город, но еще немного сохранивший дух старого времени. Но среди старых домов, с узорными деревянными наличниками возвышается несколько современных многоквартирных домов и офисов, воздвигнутых после того, как большевики взяли власть в 1915 г.» [5, p. 4]. Очевидна ошибка (или описка) журналиста в дате Октябрьской революции.

В первой части статьи видно, что А. Стил, пробывший в Куйбышеве менее недели, попытался передать американским читателям атмосферу города, используя выражения «дух старого времени», «узорные деревянные наличники». Так на основе противопоставления зданий демонстрировался контраст между дореволюционным Куйбышевом и современным. Под «современными офисами» Стил, скорее всего, имел в виду Дом промышленности, прогулки к которому иногда упоминают англо-американские мемуаристы 1941-1943 гг. [6]. Однако другую деталь города, оставившую след в воспоминаниях журналистов, - многочисленные купеческие особняки Стиль не упомянул в репортаже, посчитав, что контраст древности и современности лучше передать с помощью противопоставления «офиса» и «узорных деревянных наличников».

Далее А. Стил показывает читателям советские архитектурные черты города: «Главный городской ориентир - огромный Дворец культуры, пред этим современным сооружением стоит героическая статуя Куйбышева, взирающего на Волгу» [5, p. 4]. Хорошо заметно, какой образ города стремится создать Стил: маленькие деревянные резные домики, задавленные гигантскими бетонными конструкциями. Стоит отметить, что А. Стил был одним из немногих журналистов, акцентирующих внимание на истории переименования города: Стил два раза в начале статьи подчеркнул, что Куйбышев назван в честь одного из «революционных лидеров».

Во второй части статьи Стил характеризует город с экономической точки зрения: «После революции Куйбышев развивается как индустриальный центр и продолжает оставаться одним из центров хранения и переработки зерна на Волге. Журналист особо отмечает, что «на полях под Куйбышевом стоит несколько ветряных мельниц в голландском стиле» [5, p. 4]. К началу XXI века под Самарой осталось только одна подобная мельница в с. Бариновка, но факт, отмеченный Стилом, показывает, что у него уже в первую неделю пребывания в городе была возможность немного изучить окрестности, тогда как другие журналисты жаловались на невозможность свободно передвигаться и собирать информацию [7, p. 81-102].

Завершает обзорную статью Стила характеристика ранней самарской истории: «Возникнув в конце XVI в., Куйбышев - тогда Самара - быстро стал главным городом в Среднем Поволжье, мощным форпостом против татарского вторжения» [5, p. 4]. Указанные американским журналистом сведения давали более точные представления об истории основания города, чем публиковавшиеся ранее в англоамериканской прессе. Завершает свой исторический экскурс Стил описанием «захвата Самары чехами в 1918 г. и превращением города в штаб антиреволюционных сил» [5, p. 4]. Основные факты истории города повторяли более ранний материал Уоллеса Кэрролла, но без придания российской истории завоевательного и агрессивного оттенка.

Статья А. Стила в период 25-26 октября широко разошлась как по центральным, так и по провинциальным периодическим изданиям $[8$, р. $12 ; 9$, p. $5 ; 10$, p.4]. А центральной газете Бостона «Boston Daily Globe» материал был опубликован с небольшим дополнением: «Посол США Л. Штейнхардт и его штаб расположились в просторном, но убогом трёхэтажном здании дореволюционного винтажного стиля» [8, p. 12]. Такая характеристика здания для посольства США исходила из уст самого посла Л. Штейнхардта, крайне недовольного бытовыми условиями [11, с. 6].

Важно отметить, что недовольство обустройством жизни иностранцев в Куйбышеве просачивалось и в прессу, а также влияло на общий настрой корреспондентов, создавая негативное восприятие своего положения в городе.

Некоторые издания, несмотря на уверенные сообщения своих корреспондентов о стойкой советской обороне, прогнозируют возможность потери Москвы, Кавказа, Крыма и вероятный отъезд Сталина в Куйбышев [12, p. 1, 2]. A «Titusville Herald» 28 октября 1941 г. предполагает даже, что «Куйбышев как альтернативная столица СССР» может стать новым рубежом обороны с опорой на индустриаль- 
ные центры Урала, в случае потери прежних промышленных центров [13, p. 1]. В эти кризисные дни Куйбышев уверенно занимает место на первых полосах англо-американских периодических изданий [14, p. $1 ; 15$, p. $1 ; 16$, p. $1 ; 17$, p. 1]. Город становится действительно известным для всех американцев, которые следят за развитием событий на советскогерманском фронте.

Значимым событием 28 октября 1941 г. для формирования образа Куйбышева стала публикация новых фотографий города [18, p. 13]. При общем малом числе, фотографии Куйбышева в американской прессе выполняли существенную функцию: дополняли и корректировали визуальный образ города. И на конец октября 1941 г. все фотоснимки наиболее полно отвечали задаче формирования позитивного образа: на снимках иностранные читатели видели Куйбышев городом с красивыми, зелеными улицами, легкими деревянными зданиями и каменными особняками, перед которыми широко развернулась речная панорама. При этом тексты американских журналистов создавали несколько иной образ ледяного, заснеженного города с огромными серыми зданиями «советского типа».

Важным информационным событием периода начала ноября 1941 г. стало размещение самого крупного на данный момент материала о Куйбышеве в наиболее известном и влиятельном новостном журнале США «Тіme». Ввиду большого значения для понимания образа Куйбышева данную статью необходимо разобрать более подробно: «В американской помощи России нет ничего нового. И русские все знают о помощи США, которая всегда приходит слишком поздно. Они особенно знакомы с этим явлением в старой Самаре, которая теперь называется Куйбышев, новая столица России» [19].

Анонимный автор журнала «Тіме» прибегает к одному из наиболее распространенных способов формирования образа России - через факт американской помощи, что еще в конце XIX века использовалось в прессе США русофилами. И в прошлом тема американской помощи использовалась для актуализации образа России как исторически дружественной для США страны [20, с. 253]. А в период 18911893 гг. Самара часто появлялась в центральной прессе США как один из центров охватившего Российскую империю голода, и призывы о помощи уже тогда звучали на страницах американских газет [21, p. $10 ; 22$, p. 3]. Это во многом объясняет начало статьи в журнале «Тіме», когда автор обращается к «старой Самаре». Но здесь звучит еще один мотив о безрезультатности данной помощи, что является новым моментом в изображении России/СССР в США.

Чтобы пояснить свою начальную мысль, автор статьи обращается к истории города Куйбышев, сообщая как уже давно известные в США факты, так и указывая новые: «Самара была основана на восточном изгибе реки Волги в XVI веке, во время правления слабого царя Федора, сына Ивана Грозного. Это должна была быть крепость против степных кочевых племен» [19]. В статье повторяется уже типичный набор сведений об истории Куйбышева, но с упоминаем царя Федора. Автор не случайно указал, что это сын Ивана Грозного, т.к. образ Ивана IV часто использовался в США в период революции 1905-
1907 гг. и был хоть как-то знаком американским читателям [20, с. 650]. Привычными словами автор статьи характеризует и национально-демографический состав населения Куйбышева/Самары в исторической ретроспективе: «Сначала ее жители были в основном казаки, но в XIX веке произошел большой наплыв поляков и немцев, особенно из Данцига. Немецкая колония на Волге росла, пока не насчитывала уже более 2.500.000 человек» [19]. Данные о численном составе немцев Поволжья американским журналистом сильно преувеличены: на 1939 г. их было 451,6 тыс. человек, а во всем СССР - 1 млн 427 тыс. [23, с. 183]. Также преувеличением является указание, что почти все немцы были из Данцига. Скорее всего, город был упомянут автором журнала «Тіте» как известный американской публике «город, из-за которого началась Вторая мировая война» [24, p. 1].

Традиционными являются слова автора о климате Куйбышева: «Самара - прекрасное место для крепости, расположена на террасах на стыке рек Волги и Самары; но это было ужасное место для жизни. Заморозки приходят в середине октября. Средняя температура января составляет $9^{\circ}$ по Фаренгейту [$12,78^{\circ}$ по Цельсию]. В отдельные годы порывы ветра настолько сильны, что снег срывает с земли» [19]. Все корреспонденты США и Великобритании, побывавшие в Куйбышеве, отмечали тяжелые природные условия и очень холодные осень и зиму $[7 ; 6 ; 25]$.

Но для автора «Тіме» это не просто констатация факта или способ формирования образа «холодной России», прежде всего - это переход к основной сюжетной линии статьи: «Постоянные засухи, за которыми следует голод. Был страшный голод в 1891 году, когда не уродились рожь и пшеница. В дюжине провинций вокруг Самары голодало 30.000.000 крестьян: от них остались только кожа и кости с вспухшими животами. Большое сердце США было затронуто. Деньги были погружены на четыре судна и отплыли в Санкт-Петербург. Но Волга далеко от Миссисипи, и помощь пришла слишком поздно: тысячи русских погибли» [19]. В этом абзаце голод в России и отношение к нему США характеризуется в привычных традициях конца XIX в. [20, с. 253, 258-264]. Американская помощь голодающей России объясняется «большим сердцем», а о причинах задержки кораблей автор статьи не упоминает.

В следующем абзаце автор возвращается к теме голода: «В 1921 году был ещё один страшный голод. На этот раз 20.000.000 крестьян были на грани голода. И снова США не остались равнодушными и помогли нуждающимся. Корреспондент Уолтер Дюранти писал: «Представьте себя стоящим на углу пыльной улицы. Дома, в основном, - низкие деревянные конструкции с грязными стеклами или зияющими отверстиями, как у вырванных глаз. Напротив есть красивый дом, принадлежавший ранее богатому купцу. Просторный сад усыпан сероватоцветными кучками... неподвижными... это дети...» [19].

Упомянутый в статье Уолтер Дюранти - знаменитый британский корреспондент, работавший в СССР с 1922 по 1934 гг., автор многочисленных публикаций о Сталине, индустриализации, Красной армии и в том числе о Самаре $[26 ; 27 ; 28]$. Именно его образ голодающей Самары использует журнал 
«Time», т.к. он наиболее полно соответствовал представлениям англо-американского общества о России/СССР и восходил к традициям XIX в., где изображение смерти, грязи, голода были ключевыми маркерами по формированию концепта отсталости, чрезвычайно выгодному для общественности США, ибо с его помощью Россия противопоставлялась США и Западу в целом. И воскрешение данного образа в публикации ноября 1941 г. показывает западным читателям, что принципиальных перемен в положении дел России/СССР не произошло.

Здесь проводится еще одна важная параллель: голод прошлых лет и Вторая мировая война фактически приравниваются через реакцию общественности США на них - Америка, по мысли журналистов, обязана помогать в таких ситуациях. Это уже элемент по формированию собственной Я-концепции для англоамериканского общества, где во главу угла ставится «цивилизационная миссия». Таким образом, видно, что Самара/Куйбышев занимали в представлениях о России/СССР важное место, выполняя роль исторического центра, которому всегда помогали американцы.

В конце статьи переплетены и старые образы, и новые оценки и представления: «Посольство США отсиживается в бывшей школе. Дипломаты собрались в «Гранд отеле», где безвкусное пиво из местной пивоварни. Пока немцы еще за 600 миль на западе, дипломаты размышляли о поволжских немцах, многие из которых были депортированы в Сибирь. Пока итальянцы еще за 700 миль на юго-западе, дипломаты сидели за огромными блюдами с самарскими макаронами» [26-28].

Наиболее старым образом, актуализированным журналом «Тіме», является Сибирь как место ссылки всех неугодных, такие представления в XIX начале XX в. были наиболее типичными в американском обществе [20, с. 186]. Распространенной и ожидаемой является и характеристика пищи, на которую жаловались многие мемуаристы США [29, с. 79]. Но совершенно новой выглядит другая мысль автора: пока дипломаты находятся в безопасности и проводят время в театре, в разговорах, банкетах, - Советскому Союзу грозит реальная опасность. Любопытно, что это воззвание к чувствам долга и справедливости у иностранцев включает в себя две небольших детали о пищевой промышленности Куйбышева: «местная пивоварня» и «самарские макароны» - до статьи в «Тіmе» это не упоминалось в прессе США и Великобритании.

Завершается статься новым призывом о помощи, опять со ссылкой на авторитетного журналиста предшествующего периода: «Но эти иностранные гости должны были чувствовать в городской памяти острую необходимость в помощи. Должно быть, они слышали жалобные крики, которые Дюранти так часто слышал в Самаре два десятилетия назад: «Помощь придет слишком поздно. Мы все должны умереть» [19].

Такие эмоциональные публикации не только способствовали активизации общественного мнения союзников по вопросу предоставления помощи СССР, но и заново открывали Самару/Куйбышев англо-американской публике, показывая, что город хорошо знаком на Западе, с ним давние узы дружбы и помощи. И самое важное: достаточно крупная по объему статья в одном из наиболее читаемых и уважаемых в США журнале способствовала развитию знаний и представлений о Куйбышеве уже в мировом масштабе.

Это выглядит странным, но одно из главных событий в жизни запасной столицы периода ноября 1941 г. не попало в сводки англо-американских газет - о военном параде 7 ноября 1941 г. будут писать на Западе только несколько месяцев спустя. Весь ноябрь корреспонденты, кроме статей о ходе операций на советско-германском фронте, публиковали краткие зарисовки о собственной жизни в Куйбышеве. Причем в статьях до 23 ноября преобладает военная информация (исходящая от журналистов в Куйбышеве), а после 23 ноября - больше заметок о мирной жизни в запасной столице. Такая перемена связана с прибытием в Куйбышев главы отделения «Ассошиэйтед пресс» в СССР - Эдди Гилмора. Новый журналист сумел внести в тему Куйбышева новые элементы.

6 декабря 1941 г. сразу в нескольких периодических изданиях США выходит статья Э. Гилмора, посвященная очень неожиданной теме - «Ночная жизнь Куйбышева» [30, р. 5; 31, р. 5; 32, р. 10; 33, p. 10]. Гилмор начинает её словами: «Ночь очень долгая в Куйбышеве, альтернативной столице СССР, потому что солнце рано ускользает на запад за свинцовую Волгу. Но ночная жизнь крайне ограничена» $[31$, p. 5]. Журналист, используя образы ночи и реки, рисует для читателей образ очень мрачного, серого и серьезного города, т.к. отсутствие ночной жизни для большинства американских граждан означало и отсутствие веселья, радости.

Однако Гилмор показывает, что ночная жизнь все-таки есть: «Центр ночной активности - «Гранд отель», где собираются журналисты, дипломаты, солдаты. Это серое здание выходит на главную улицу города, фасадом на реку. В отеле играют американские мелодии, но, по правде сказать, семеро музыкантов превосходят своим числом танцующих дам» $[31$, р. 5]. Здесь Гилмор показывает читателям, что вторая главная трудность, с которой столкнулись иностранцы в Куйбышеве, - это отсутствие привычных развлечений. Необходимо отметить, что прожившие долгие годы в СССР Генри Шапиро и Уолтер Керр чрезвычайно редко жаловались в статьях подобным образом, а про собственные развлечения в то время, когда СССР вел войну, старались совсем не писать.

Гилмор успешно разоблачает миф о недостатке еды для иностранцев, который уже успел сформироваться в прессе США благодаря публикации жалоб Л. Штейнхардта. Гилмор пишет: «Вы можете заказать себе прекрасную еду за 4-5 долларов: хлеб, масло, ягненок, цыпленок, гусь, баранина, осетр, сельдь, великолепные супы, выпечка, чай, пиво и водка» [31, p.5]. Перечисление всего изобилия и цен звучало более убедительно, чем бездоказательные жалобы американского посла. И в этот перечень не попали еще мясные деликатесы, колбасы, икра, которая была у посла и генералитета США [29, с. 79]. Таким образом, благодаря Гилмору общественность США смогла получить более точную информацию об организации питания для эвакуированных иностранцев в Куйбышеве.

После восхищенной характеристики еды Гилмор в статье переходит снова к развлечениям, упоминая, 
что «уличная жизнь в Куйбышеве - это смесь льда, Азии, Европы и переполненных улиц» [31, p. 5]. Видимо, это наиболее яркая и образная оценка Куйбышева 1941 г., которая была близка и понятна, а главное, ожидаема для практически любого иностранца.

В целом, содержательная статья Гилмора открывала перед англо-американской общественностью новые черты города на Волге, тогда как ноябрьская статья в журнале «Тіте» - новые факты из его истории. Однако значительно повлиять на процесс формирования образа Куйбышева указанный материал Гилмора не совсем успевает: 7 декабря 1941 г. происходит нападение Японии на Пёрл-Харбор, США вступают во Вторую мировую войну, и интерес американской прессы переключается на Тихий океан.

В итоге, за период с 20 октября по 6 декабря 1941 г. практически неизвестный широкой американской публике Куйбышев превратился в третий по значению и (что немаловажно) по узнаваемости город СССР. Журналистам союзников удалось в такие короткие сроки не только создать образ города, сделать его более понятным и близким для своих читателей, но и связать Куйбышев с Самарой, показать, объяснить общественности, что это один и тот же город, одно и то же историческое место, имеющее богатое прошлое, в том числе и связанное с США.

Интересная дополнительная информация о Куйбышеве содержится в архивах Федерального бюро расследований США. Так, в деле знаменитого ученого Николы Теслы содержится несколько упоминаний о запасной столице. С момента усиления ФБР в 1930х гг. Тесла, долгое время проработавший в США, попал под внимание этой службы. С началом войны ученый усилил контакты с посольством своей родной Югославии. В одном из отчетов агентов встречается упоминание о том, что в Куйбышеве размещено не просто посольство этой страны, а все ее правительство, с которым Тесла пытается войти в контакт для оказания посильной помощи своим соотечественникам. Также в отчете дается краткая справка о положении СССР в разразившейся войне и подчеркивается, что Куйбышев стал не просто резервной столицей, но и важным центром международных отношений [34].

Также Куйбышев встречается в деле генерального секретаря ЦК КПСС Л.И. Брежнева. Хотя в основе своей ФБР - контрразведывательная организация, ее амбиции простирались и в область разведки, что и послужило причиной создания досье на многих зарубежных политиков. Упоминания Куйбышева встречаются в 1 и 2 частях досье, посвященных военному пути Брежнева. Не имея об этом периоде никаких конкретных сведений, федеральные агенты собирали любые упоминания о СССР в американской прессе. В этой части архива практически отсутствуют аналитические отчеты. Лишь в двух коротких записках, по одной на каждую часть досье, упоминается, что Брежнев в качестве третьего секретаря обкома г. Днепропетровска участвует в эвакуации части производственных мощностей в Куйбышев. Также указано, что, поступив на военную службу в качестве бригадного комиссара, Л.И. Брежнев недолгое время продолжает участвовать в работе по эвакуации промышленности СССР в Куйбышев. Наиболее важным в данных записках становится указание на то, что Куйбышев, сосредоточивший основные производ- ства СССР, стал не только важнейшим политическим центром, но и главным промышленным центром Советской России [35].

В целом архивы ФБР показывают, что мнение американских спецслужб о Куйбышеве во многом было продиктовано его статусом запасной столицы, информацией из прессы и общей неразберихой, царившей в мире в первый период Второй мировой войны.

\section{СПИСОК ЛИТЕРАТУРЫ:}

1. Modesto Bee And News-Herald. 1941. October 22.

2. Fitchburg Sentinel. 1941. October 22.

3. Abilene Reporter-News. 1941. October 22.

4. Albuquerque Journal. 1941. October 23.

5. Los Angeles Times. 1941. October 25.

6. Cassidy H. Moscow Dateline: 1941-1943. Boston, 1943.

7. Gilmore E. Me and My Russian Wife. New York, 1954.

8. Boston Daily Globe. 1941. October 26.

9. Deseret News. 1941. October 25.

10. Lewiston Morning Tribune. 1941. October 25.

11. Алексушин Г.В. Война и мир // Университетский проспект. 1999. № 6 (21).

12. Galveston Daily News. 1941. October 26.

13. Titusville Herald. 1941. October 26.

14. Nevada State Journal. 1941. October 28.

15. Galveston Daily News. 1941. October 28.

16. Syracuse Herald-Journal. 1941. October 28.

17. Derrick Oil City. 1941. October 28.

18. Wisconsin Rapids Daily Tribune. 1941. October 28.

19. Samara's Memories // Time. 1941. November 3. Vol. XXXVIII.

20. Журавлёва В.И. Понимание России в США: образы и мифы: 1881-1914. М.: РГГУ, 2012. 1136 с.

21. New York Times. 1892. March 10.

22. New York Times. 1892. February 27.

23. Кабузан В.М. Немецкоязычное население в Российской империи и СССР в XVIII-XX вв. (17191989 гг.): Историко-статистическое исследование. М.: ИРИ РАН, 2003. 218 c.

24. Milwaukee Journal. 1.09.1939.

25. Carroll W. Inside Warring Russia: An EyeWitness Report on the Soviet Union's Battle. New York, 1942.

26. Duranty W. The Kremlin and the People. New York, 1941.

27. Duranty W. Duranty Reports Russia. New York, 1934.

28. Duranty W. Red Economics. New York, 1932.

29. Дин Дж. Странный союз. М., 2005.

30. Washington Post. 1941. 1941. December 6.

31. Chicago Daily Tribune. 1941. December 6.

32. Abilene Reporter-News. 1941. December 6.

33. The Independent Record. 1941. December 6.

34. NARA. RG. 65. Federal Bureau of Investigation, File: 100-2237, part 1 (Nikola Tesla file).

35. NARA. RG. 65. Federal Bureau of Investigation, File: 105-86659, part 1, 2 (Leonid Ilyich Brezhnev file).

Статья выполнена при поддержке РГНФ (проекm 17-11-63001) 


\title{
THE ALTERNATIVE CAPITAL OF THE USSR: ESTIMATES OF THE AMERICAN PRESS AND SPECIAL SERVICES
}

(C) 2017

\author{
Buranok Sergey Olegovich, doctor of historical sciences, \\ associate professor of World History, Law and Methods of Teaching Department \\ Levin Yaroslav Alexandrovich, candidate of historical sciences, \\ junior researcher of World History, Law and Methods of Teaching Department \\ Sokolova Anna Vyacheslavovna, student of History Faculty \\ Samara State University of Social Sciences and Education (Samara, Russian Federation)
}

Abstract. The following paper for the first time in Samara regional studies deals with the study of significance of Kuibyshev in the public opinion of the USSR allies. Having become a reserved capital, Kuibyshev ceased to be just one of the regional centers in the Soviet Union, it turned into a city known and significant all over the world. This paper uses many unique US documents on Kuibyshev during the war. On their basis the authors analyze formation and perception of the image of the reserved capital in American society. To study the history of Kuibyshev as a second capital at such an angle is important for imagology, study of local lore and comparative studies. The conducted research showed how the image of Kuibyshev was made in the conditions of the Second World War, how its perception changed. The paper also uses the data of the US special services that makes it possible to understand what place Kuibyshev was given at that time by representatives of the intelligence community of America. The study of Kuibyshev image in the assessments of the American special services opens a possibility for researchers to get acquainted with their work from a new perspective. The paper draws conclusions about the influence of certain journalists on the formation of Kuibyshev image. The conclusions drawn in this paper, as well as the introduction of new documents into circulation, will allow us to deepen and expand this topic in the future.

Keywords: Second World War; Great Patriotic War; Kuibyshev; Samara; Samara Region; Imagology; alternative capital; Federal Bureau of Investigation; Associated Press; USA; Henri Cassidy; Eddie Gilmour; Henry Shapiro; Walter Kerr; Archibald Steele; special services; Pearl Harbor; Pacific War.

УДК 94(470.41) "1941/1945"

\section{СОЦИАЛЬНАЯ АДАПТАЦИЯ И ТРУДОУСТРОЙСТВО ИНВАЛИДОВ В ГОДЫ ВЕЛИКОЙ ОТЕЧЕСТВЕННОЙ ВОЙНЫ (НА МАТЕРИАЛАХ ТАТАРСКОЙ АССР)}

(C) 2017

\author{
Кабирова Айслу Шарипзяновна, доктор исторических наук, \\ ведущий научный сотрудник отдела новейшей истории \\ Институт истории им. Ш. Марджани Академии наук Республики Татарстан \\ (2. Казань, Российская Федерация)
}

Аннотация. В статье рассматриваются проблемы социальной адаптации инвалидов Великой Отечественной войны в Татарской АССР после возвращения их к мирной жизни. На основе документальных материалов, извлеченных из фондов федеральных и татарстанских архивов, характеризуются формы государственной поддержки искалеченных войной людей, решение вопросов их производственного обучения и трудоустройства, назначения пенсий, открытия домов-интернатов, организации медико-санитарного обслуживания и т.д. Отмечается, что для большинства инвалидов такая адресная поддержка являлась зачастую определяющей в обеспечении их жизнедеятельности. Трудоустройство инвалидов Отечественной войны позволяло решить двуединую задачу - в условиях острого дефицита рабочих рук создавался новый кадровый резерв для экономики и одновременно обеспечивалась социальная защита вернувшихся после лечения в госпиталях фронтовиков. Многие инвалиды Великой Отечественной войны хорошо зарекомендовали себя на производстве. Они становились передовиками, выдвигались на руководящие должности. Но были и те, кто вел аморальный образ жизни, занимался попрошайничеством. Властные органы, призванные решать вопросы социальной реабилитации инвалидов, не всегда справлялись с возложенными на них задачами. Свидетельством этого являются зафиксированные в источниках факты бездушно-бюрократического отношения отдельных чиновников к нуждам и запросам инвалидов, случаи присваивания денежных средств и разбазаривания государственных фондов.

Ключевые слова: Великая Отечественная война; Татарская АССР; фронтовики; инвалиды войны; адресная поддержка; государственная помощь; социальная адаптация; социальная защита; реабилитация; пенсии; пособия; трудовая политика; производственное обучение; трудоустройство; интернаты для инвалидов.

История не знала примеров столь массового героизма, какой проявили советские воины в годы Великой Отечественной войны. Ратные подвиги фронтовиков до сих пор остаются предметом восхищения и изучения как отечественных историков, так и зару- бежных специалистов. Но стойкость, мужество и доблесть бойцов во время ожесточенных столкновений с противником нередко сопровождались тяжелыми ранениями и травмами. Немало увечий получали и мирные жители от боевых действий в приф- 